\title{
Assessment of Equal and Unequal Amplitude Carriers for a $1 \Phi$ Five Level Flying Capacitor Multilevel Inverter
}

\author{
P.Sureshpandiarajan, S.P.Natarajan*, C.R.Balamurugan, K.Ramasamy \\ P.S.R Rengasamy College of Engineering for Women, Sivakasi, India \\ ${ }^{*}$ Corresponding author, e-mail: spn_annamalai@rediffmail.com
}

\begin{abstract}
This work presents the comparison of various Pulse Width Modulation (PWM) techniques for the chosen single phase half bridge FCMLI (Flying Capacitor Multi Level Inverter). In this paper, a single phase half bridge flying capacitor multilevel inverter is controlled with sinusoidal, THI (Third Harmonic Injection), Trapezoidal and TAR (Trapezoidal Amalgamated Reference) reference with Equal Amplitude Carriers (EAC) and UEAC (Un Equal Amplitude Carriers). The proposed EAC and UEAC is applied for various PWM strategies. The PWM methods used for the analysis are PD (Phase Disposition) PWM, POD (Phase Opposition and Disposition) PWM, APOD (Alternative Phase Opposition and Disposition) PWM and $C O$ (Carrier Overlapping) PWM with EAC and UEAC. For all the PWM methods and references the UEAC produces less THD and higher fundamental RMS (Root Mean Square) values except for $m_{a}=1$. For $m_{a}=1$ the EAC provides less THD (Total Harmonic Distortion) and higher fundamental RMS (Root Mean Square) values for all the PWM methods and references. To validate the developed technique, simulations are carried out through Power System Block Set.
\end{abstract}

Keywords: VAPWM, 60 degree PWM, TAR, THD, FCMLI.

Copyright $\odot 2015$ Institute of Advanced Engineering and Science. All rights reserved.

\section{Introduction}

FCMLI is a multiple voltage level inverter topology which uses capacitors (called flying capacitors) for clamping the voltage across the power semiconductor devices. DCMLI has much difficulty beyond four levels in output voltage in controlling or balancing voltage of each capacitor constituting DC-link. DCMLI is hard to be expanded to high level systems structurally due to large number of clamping diodes. FCMLI does not require isolated DC sources and additional clamping diodes. FCMLI topology can be easily expanded to high level systems. FCMLI offers also a great advantage with respect to the availability of voltage redundancies. On the other hand FCMLI has a drawback due to the need for providing additional flying capacitors and balancing control of flying capacitor voltages. Various multi-carrier PWM strategies are developed and simulated using MATLAB-SIMULINK for chosen three phase FCMLI. Chiasson [1] proposed the method to eliminate harmonics in a switching converter is considered. That is, given a desired fundamental output voltage, the problem is to find the switching times (angles) that produce the fundamental while not generating specifically chosen harmonics. In contrast to the well known work of Patel and Hoft and others, here all possible solutions to the problem are found. This is done by first converting the transcendental equations that specify the harmonic elimination problem into an equivalent set of polynomial equations. Juan and Moran [2] focussed on minimizing the number of power supplies and semiconductors for a given number of levels. Multilevel inverters with a large number of steps (more than 50 levels) can generate high quality voltage waveforms, good enough to be considered as suitable voltage template generators. Many levels or steps can follow a voltage reference with accuracy, and with the advantage that the generated voltage can be modulated in amplitude instead of pulse-width modulation. The main disadvantage of this type of topology is the large number of power supplies and semiconductors required to obtain these multistep voltage waveforms. Wells et al [3] suggested calculating easily and quickly the desired waveform without solution of coupled transcendental equations. A modulation-based method for generating pulse waveforms with selective harmonic elimination is proposed. Harmonic elimination, traditionally digital, is shown to be achievable by comparison of a sine wave with modified triangle carrier. Urmila and Subbarayudu [4] presents a comparative study of nine level diode clamped inverter for constant 
Switching frequency of sinusoidal Pulse width Modulation and sinusoidal Natural Pulse width Modulation with switching frequency Optimal Modulation. Khoucha et al [5] presents the comparison study for a cascaded $\mathrm{H}$-bridge multilevel direct torque control (DTC) induction motor drive. Earlier studies have pointed out the limitations of conventional inverters, especially in high-voltage and high-power applications. In recent years, multilevel inverters are becoming increasingly popular for high-power applications due to their improved harmonic profile and increased power ratings. Several studies have been reported in the literature on multilevel inverters topologies, control techniques, and applications. However, there are few studies that actually discuss or evaluate the performance of induction motor drives associated with threephase multilevel inverter. Nami et al [6] proposed a comparative study has been carried out to present high performance of the proposed configuration to approach a very low total harmonic distortion of voltage and current, which leads to the possible elimination of the output filter. A novel $\mathrm{H}$-bridge multilevel pulse width modulation converter topology based on a series connection of a high-voltage diode-clamped inverter and a low-voltage conventional inverter is proposed in this paper. A dc link voltage arrangement for the new hybrid and asymmetric solution is presented to have a maximum number of output voltage levels by preserving the adjacent switching vectors between voltage levels. Hence, a 15-level hybrid converter can be attained with a minimum number of power components. Kangarlu et al $[7,8]$ proposes a new topology based on the non-insulated dc voltage sources for multilevel inverter with reduced number of switching devices. Multilevel inverters have an important portion in power processing in power systems. Babaei et al $[9,10]$ developed a new general cascaded multilevel inverter using $\mathrm{H}$-bridges is proposed. The proposed topology requires a lesser number of dc voltage sources and power switches and consists of lower blocking voltage on switches, which results in decreased complexity and total cost of the inverter. These abilities obtained within comparing the proposed topology with the conventional topologies from aforementioned points of view. Moreover, a new algorithm to determine the magnitude of dc voltage sources is proposed.

\section{Flying Capacitor Multilevel Inverter}

Figure 1 shows the general structure of half bridge five level flying capacitor inverter for R-phase. FCMLI requires 8 semiconductor switches (S1-S4, S1'-S4') 3 flying capacitors (C3', C4', C5') and 2 DC link capacitors (C1', C2'). This FCMLI consists of four switch pairs (S1, S1'), $\left(\mathrm{S} 2, \mathrm{~S}^{\prime}\right),\left(\mathrm{S} 3, \mathrm{~S}^{\prime}\right)$ and $\left(\mathrm{S} 4, \mathrm{~S} 4^{\prime}\right)$. The switches are clamped by DC-link together with flying capacitors. The four switches (S1-S4) must be connected in series between DC input and load and likewise for switches (S4'-S1'). The three flying capacitors C3', C4' and C5' are charged to different voltage levels. By changing the transistor switching states, the capacitors and the DC source are connected in different ways to produce different load voltage levels. A typical switch combination used to synthesize the various load voltages are shown in Table 1.

Table 1 also indicates the state of the flying capacitor corresponding to the switch combination chosen. Charging of a capacitor is indicated by '+', discharging by '-' while NC indicates neither charging nor discharging. By proper selection of capacitor combinations, it is possible to balance the capacitor charge. The capacitor states (+ and -) will reverse for the negative current. The flying capacitor five level inverter is modeled in SIMULINK using power system block set. Switching signals for chosen FCMLI are developed using PWM techniques discussed previously. Simulations are performed with different values of $m_{a}$ ranging from 0.6 to 1 and resistive load of $100 \Omega$. Simulated output voltages of chosen MLI with various strategies are displayed only for a sample value of $m_{a}=0.8$. In this chapter $m_{f}$ is chosen as 20 as a trade off in view of the following reasons: (i) to reduce switching losses (which may be high at large $m_{f}$ ) (ii) to reduce the size of the filter needed for the closed loop control, the filter size being moderate at moderate frequencies (iii) to effectively utilize the available dSPACE system for hardware implementation. FCMLIs are especially well designed for applications where the number of output voltage levels is high. The applications of FCMLI are fans and pumps, compressors, conveyors, mills, mine winding machines, propulsion drives in marine applications and metal industries. Appropriate PWM strategies may be employed depending on the performance measure required in a particular application. 


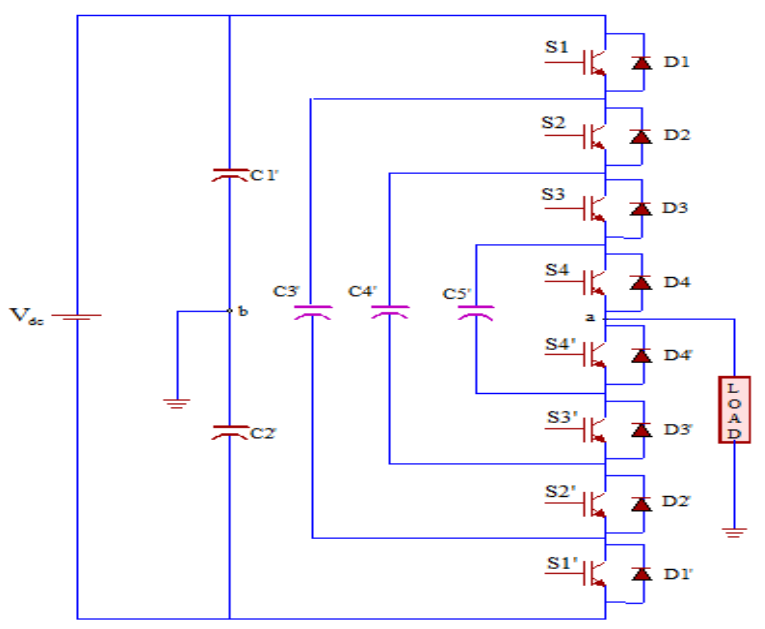

Figure 1. Half bridge five level flying capacitor inverter

Table 1. Switch states and output voltage levels for one phase of flying capacitor inverter

\begin{tabular}{|c|c|c|c|c|c|c|c|}
\hline S1 & S2 & S3 & S4 & C3' & C4' & C5' & $\mathbf{V}_{\mathrm{an}}$ \\
\hline 1 & 1 & 1 & 1 & $\mathrm{NC}$ & $\mathrm{NC}$ & $\mathrm{NC}$ & $+\mathrm{V}_{\mathrm{dc}} / 2$ \\
\hline 1 & 1 & 1 & 0 & $\mathrm{NC}$ & $\mathrm{NC}$ & + & \\
\hline 1 & 1 & 0 & 1 & $\mathrm{NC}$ & + & - & \\
\hline 1 & 0 & 1 & 1 & + & - & $\mathrm{NC}$ & $+\mathrm{V}_{\mathrm{dc}} / 4$ \\
\hline 0 & 1 & 1 & 1 & - & $\mathrm{NC}$ & $\mathrm{NC}$ & \\
\hline 0 & 0 & 1 & 1 & $\mathrm{NC}$ & - & $\mathrm{NC}$ & \\
\hline 0 & 1 & 0 & 1 & - & + & - & \\
\hline 0 & 1 & 1 & 0 & - & $\mathrm{NC}$ & + & \\
\hline 1 & 0 & 0 & 1 & + & $\mathrm{NC}$ & - & 0 \\
\hline 1 & 0 & 1 & 0 & + & - & + & \\
\hline 1 & 1 & 0 & 0 & $\mathrm{NC}$ & + & $\mathrm{NC}$ & \\
\hline 1 & 0 & 0 & 0 & + & $\mathrm{NC}$ & $\mathrm{NC}$ & \\
\hline 0 & 1 & 0 & 0 & - & + & $\mathrm{NC}$ & \\
\hline 0 & 0 & 1 & 0 & $\mathrm{NC}$ & - & + & $-\mathrm{V}_{\mathrm{dc}} / 4$ \\
\hline 0 & 0 & 0 & 1 & $\mathrm{NC}$ & $\mathrm{NC}$ & - & \\
\hline 0 & 0 & 0 & 0 & $\mathrm{NC}$ & $\mathrm{NC}$ & $\mathrm{NC}$ & $-V_{d c} / 2$ \\
\hline
\end{tabular}

\section{Modulation Strategies}

Several CFDs exist in multi-carrier PWM strategies for MLIs. These strategies have more than one carrier option that can be triangular, saw tooth, a new function etc. As far as the particular carrier signals are concerned, there are multiple CFDs including function, frequency, amplitude, phase of each carrier and offset between carriers. Although multilevel inverter offers several advantages, the control strategies of MLI are quite challenging due to the complexity to cater the transitions between the voltage levels (or steps). A number of modulation strategies are used in multilevel power conversion applications. In this proposed topology two methods are used.

1. Equal Amplitude Carriers

2. Un Equal Amplitude Carriers (or) Variable Amplitude Carriers (VAC)

\subsection{Equal Amplitude Carriers}

In this method, all the triangular carriers used will have the same amplitude. The PWM methods used are PDPWM, PODPWM, APODPWM and COPWM with sine, THI, trapezoidal, TAR and stepped wave references. Figure 2 to 4 shows the sample carrier arrangement, output voltage and FFT plot for PDPWM strategy with sine reference $\left(m_{a}=0.8\right.$ and $\left.m_{f}=20\right)$. Where $m_{a}$ and $\mathrm{m}_{\mathrm{f}}$ are the amplitude and frequency modulation index. 


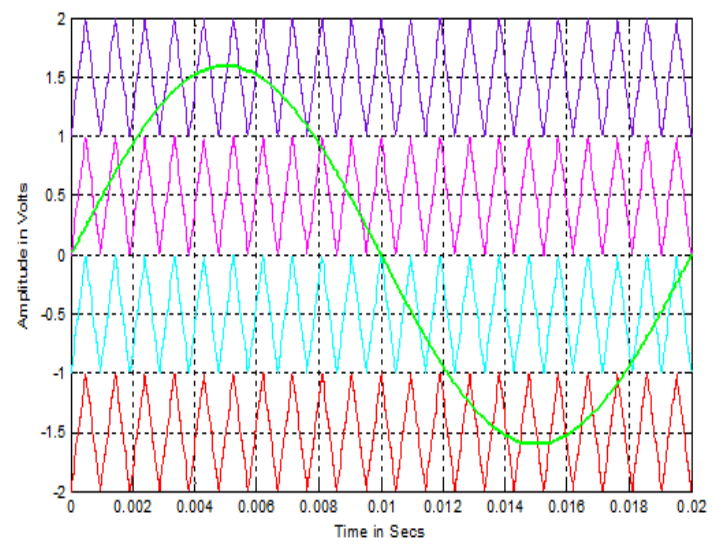

Figure 2. Sample carrier arrangement for equal amplitude carriers with PDPWM strategy

(sine reference for $m_{a}=0.8$ and $m_{f}=20$ )

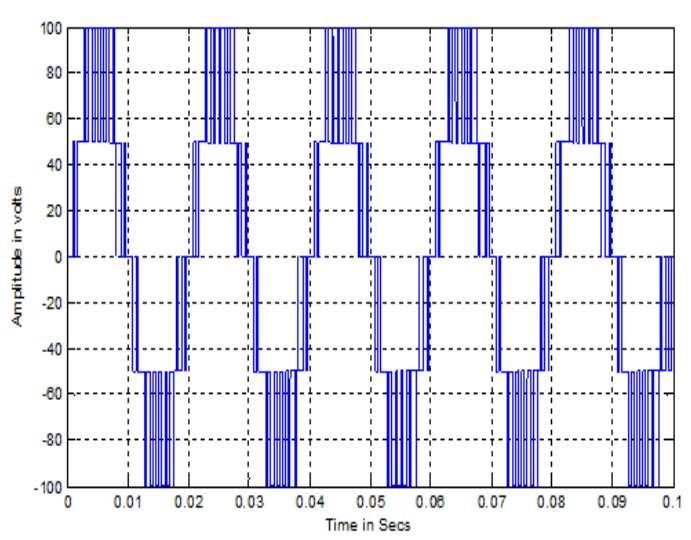

Figure 3. Sample Output voltage of five level inverter based on equal amplitude carriers with PDPWM strategy (sine reference for $\mathrm{m}_{\mathrm{a}}=$ 0.8 and $\mathrm{m}_{\mathrm{f}}=20$ )

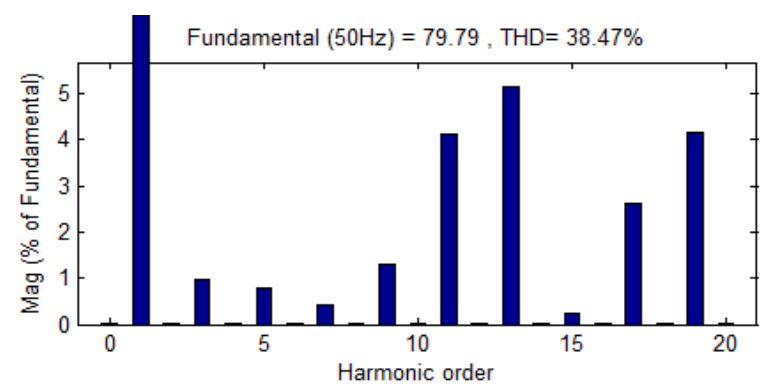

Figure 4. Sample THD plot for five level output voltage based on equal amplitude carriers with PDPWM strategy (sine reference for $m_{a}=0.8$ and $m_{f}=20$ )

\subsection{Un Equal Amplitude Carriers (or) Variable Amplitude Carriers (VAC)}

In this method, all the triangular carriers used will not have the same amplitude. The PWM methods used are UEAPD (Un Equal Amplitude Phase Disposition) PWM, UEAPODPWM, UEAAPODPWM and UEACOPWM with sine, THI, trapezoidal and TAR references. Figure 5 to 7 shows the sample carrier arrangement, output voltage and FFT plot for PDPWM strategy with sine reference $\left(m_{a}=0.8\right.$ and $\left.m_{f}=20\right)$. Figure 8 to 10 show the sample reference waveforms. $m_{a}$ is varied from 1 to 0.6 for equal amplitude carrier methods. In EAC method if $m_{a}$ is varied from 1 to 0.51 then the inverter will work as a five level inverter and if the $\mathrm{m}_{\mathrm{a}}$ is varied from 0.5 to zero then the inverter will work as a three level inverter. But in case of UEAC method if $\mathrm{m}_{\mathrm{a}}$ is varied from 1 to 0.26 then the inverter will work as a five level inverter and if the $m_{a}$ is varied from 0.25 to zero then the inverter will work as a three level inverter.

Where,

$$
\begin{aligned}
& m_{a}=\frac{A_{m}}{A_{c}} \\
& m_{f}=\frac{f_{c}}{f_{m}}
\end{aligned}
$$

$m_{\mathrm{f} 1}$ - Frequency modulation index for upper and lower carriers.

$\mathrm{m}_{\mathrm{f} 2}$ - Frequency modulation index for intermediate carriers. 


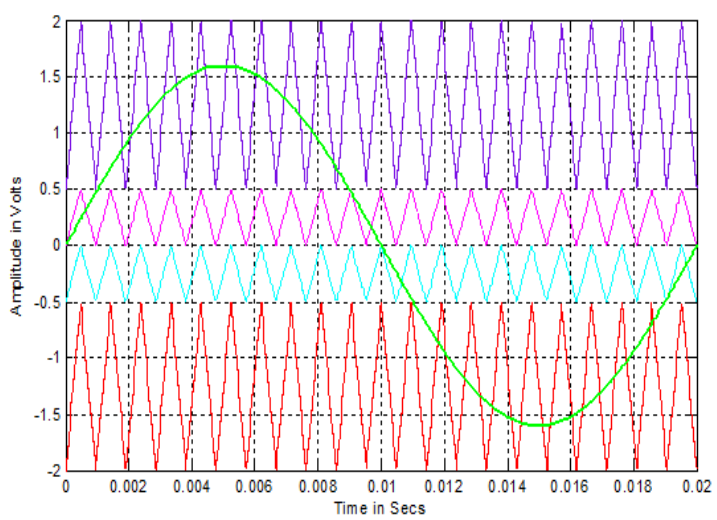

Figure 5. Sample carrier arrangement for unequal amplitude carriers with PDPWM strategy (sine reference for $\mathrm{m}_{\mathrm{a}}=0.8$ and $\mathrm{m}_{\mathrm{f}}$ $=20$ )

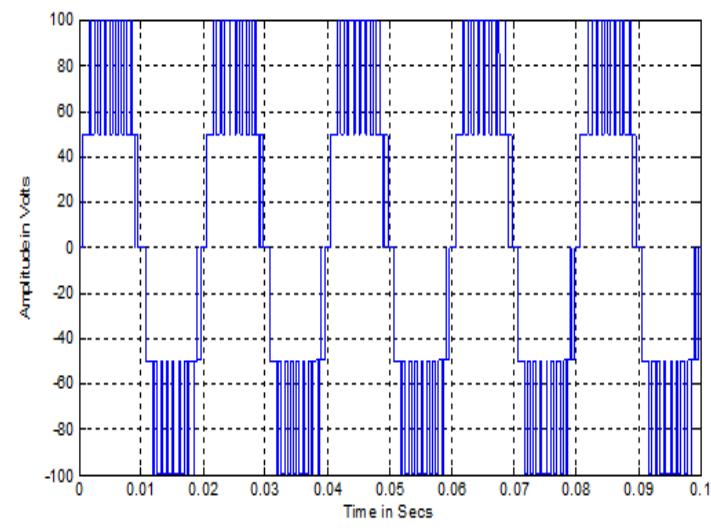

Figure 6. Sample output voltage of five level inverter based on unequal amplitude carriers with PDPWM strategy (sine reference for $m_{a}=$ 0.8 and $\mathrm{m}_{\mathrm{f}}=20$ )

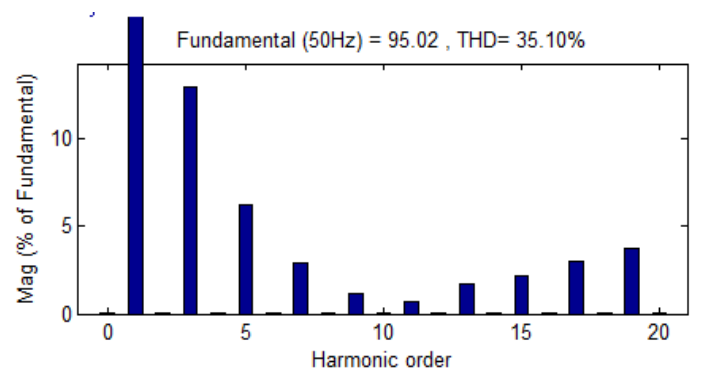

Figure 7. Sample THD plot for five level output voltage based on unequal amplitude carriers with PDPWM strategy (sine reference for $m_{a}=0.8$ and $m_{f}=20$ )

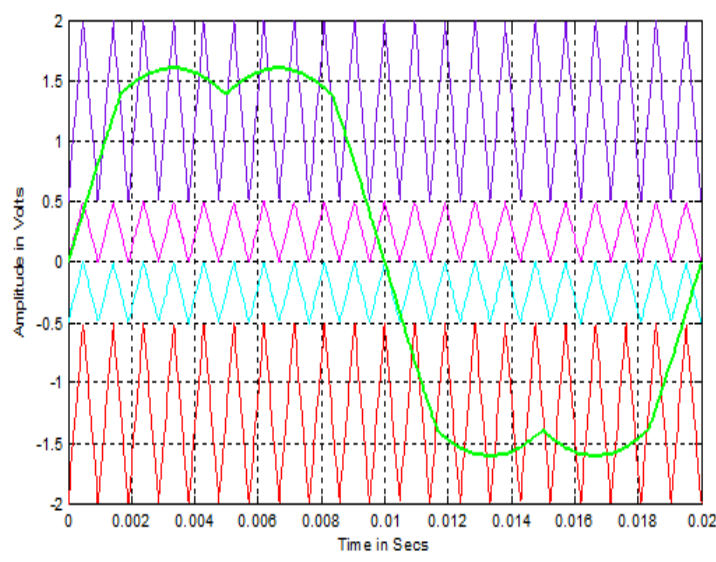

Figure 8. Sample carrier arrangement for unequal amplitude carriers with PDPWM strategy (THI reference for $m_{a}=0.8$ and $m_{f}$ =20)

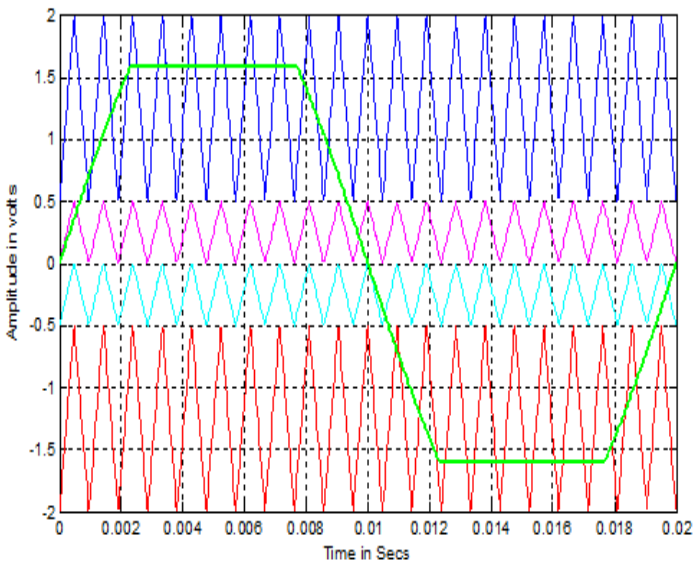

Figure 9. Sample carrier arrangement for unequal amplitude carriers with PDPWM strategy (trapezoidal reference for $\mathrm{m}_{\mathrm{a}}=0.8$ and $m_{f}=20$ ) 


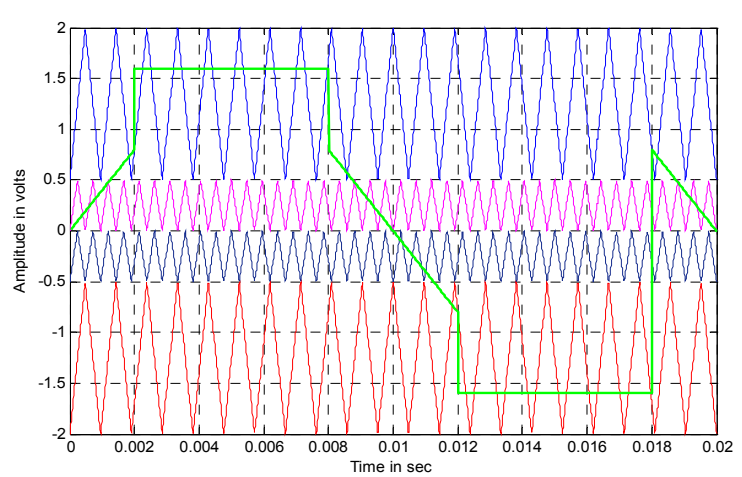

Figure 10. Sample carrier arrangement for unequal amplitude carriers with PDPWM strategy $\left(\right.$ TAR reference for $m_{a}=0.8$ and $\left.m_{f}=20\right)$

\section{Simulation Results}

The following parameters are used for the simulation $V_{d c}=200 \mathrm{~V}, \mathrm{R}$ (Resistance) $=100$ ohms, C1' $=\mathrm{C} 2{ }^{\prime}=4700 \mu \mathrm{F}, \mathrm{C} 3^{\prime}=1000 \mu \mathrm{F}, \mathrm{C} 4{ }^{\prime}=1500 \mu \mathrm{F}, \mathrm{C5}^{\prime}=3000 \mu \mathrm{F}, \mathrm{A}_{\mathrm{c}}$ (Amplitude of the carrier signal) $=0.5,1$ and $1.5, A_{m}$ (Amplitude of the modulating signal $=2, \mathrm{f}_{c}$ (frequency of the carrier signal) $=1000 \mathrm{~Hz}$ and $2000 \mathrm{~Hz}$ and $\mathrm{f}_{\mathrm{m}}$ (frequency of the modulating signal) $=50 \mathrm{~Hz}$. Table 1 and 2 shows the THD and $\mathrm{V}_{\mathrm{RMS}}$ values for the proposed five level inverter. In tables it is represented as 3-level for $m_{a}=0.5$ to 0.3 . The equal amplitude carrier methods will give five levels only up to $\mathrm{m}_{\mathrm{a}}=0.59$ but the UEAC method will give five levels up to $\mathrm{m}_{\mathrm{a}}=0.26$. The tables compare the total harmonic distortion and voltage in terms of RMS for various references and carriers.

Table 2. \%THD for five level output voltage based on equal amplitude and unequal amplitude carriers with various modulation indices

\begin{tabular}{|c|c|c|c|c|c|c|c|c|c|}
\hline \multirow{3}{*}{ Ref. } & \multirow{3}{*}{$\mathrm{m}_{\mathrm{a}}$} & \multicolumn{8}{|c|}{$\%$ THD for 5-level inverter } \\
\hline & & \multicolumn{2}{|c|}{ PDPWM } & \multicolumn{2}{|c|}{ PODPWM } & \multicolumn{2}{|c|}{ APODPWM } & \multicolumn{2}{|c|}{ COPWM } \\
\hline & & PD & UEAPD & POD & UEAPOD & APOD & UEAAPOD & $\mathrm{CO}$ & UEACO \\
\hline \multirow{8}{*}{ 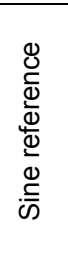 } & 1 & 26.85 & 27.55 & 26.57 & 27.35 & 26.85 & 27.21 & 26.85 & 30.22 \\
\hline & 0.9 & 33.11 & 31.52 & 32.66 & 31.74 & 33.11 & 31.81 & 33.11 & 34.43 \\
\hline & 0.8 & 38.47 & 35.10 & 37.66 & 35.38 & 38.47 & 35.36 & 38.47 & 37.90 \\
\hline & 0.7 & 42.02 & 38.21 & 41.85 & 38.19 & 42.02 & 38.25 & 42.02 & 40.68 \\
\hline & 0.6 & 44.51 & 39.61 & 43.45 & 39.70 & 44.51 & 39.60 & 44.51 & 43.58 \\
\hline & 0.5 & & 40.62 & & 40.51 & & 40.59 & & 46.2 \\
\hline & 0.4 & ले $\stackrel{D}{0}_{0}$ & 40.53 & लं $\stackrel{D}{0}_{0}-$ & 42.70 & ले $\stackrel{0}{\gg}-$ & 40.38 & 'ं $\stackrel{D}{0}_{0}^{\infty}$ & 49.31 \\
\hline & 0.3 & & 42.57 & & 43.52 & & 41.5 & & 60.03 \\
\hline \multirow{8}{*}{ 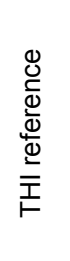 } & 1 & 27.58 & 32.18 & 28 & 32.30 & 28.09 & 32.49 & 33.28 & 33.55 \\
\hline & 0.9 & 35.53 & 35.72 & 35.80 & 35.62 & 35.8 & 35.82 & 37.94 & 37.64 \\
\hline & 0.8 & 41.34 & 39.84 & 41.40 & 39.99 & 41.43 & 39.91 & 41.52 & 41.49 \\
\hline & 0.7 & 43.92 & 43.26 & 43.77 & 43.27 & 43.92 & 43.18 & 45.87 & 44.73 \\
\hline & 0.6 & 43.08 & 45.41 & 42.92 & 45.56 & 43.05 & 45.54 & 52.52 & 47.46 \\
\hline & 0.5 & & 45.54 & & 46.06 & & 45.84 & & 48.80 \\
\hline & 0.4 & 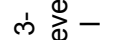 & 44.80 & 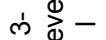 & 44.87 & ம் $\stackrel{D}{0}_{0}$ & 44.89 & 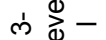 & 48.61 \\
\hline & 0.3 & & 39.20 & & 39.2 & & 39.27 & & 51.38 \\
\hline \multirow{8}{*}{ 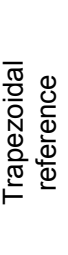 } & 1 & 22.36 & 26.48 & 22.40 & 26.49 & 22.45 & 26.58 & 29.41 & 29.25 \\
\hline & 0.9 & 31.50 & 32.08 & 31.42 & 32.25 & 31.67 & 32.13 & 34.33 & 34.02 \\
\hline & 0.8 & 37.50 & 36.68 & 37.62 & 36.84 & 37.37 & 36.80 & 39.58 & 38.49 \\
\hline & 0.7 & 41.85 & 40.22 & 41.77 & 40.28 & 41.96 & 40.39 & 44.12 & 42.04 \\
\hline & 0.6 & 42.18 & 42.52 & 42.37 & 42.68 & 42.28 & 42.71 & 48.75 & 45.11 \\
\hline & 0.5 & & 44.13 & & 44.14 & & 44.24 & & 46.78 \\
\hline & 0.4 & ले $\stackrel{D}{0}_{0}$ & 43.23 & लं $\stackrel{D}{0}_{0}-$ & 43.04 & ले $\stackrel{0}{\gg}-$ & 43.10 & ले $\stackrel{D}{0}_{0}^{\infty}-$ & 48.07 \\
\hline & 0.3 & & 39.12 & & 39.22 & & 39.17 & & 48.71 \\
\hline \multirow{8}{*}{ 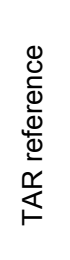 } & 1 & 34.76 & 37.50 & 34.67 & 37.70 & 34.67 & 36.29 & 42.29 & 38.98 \\
\hline & 0.9 & 42.96 & 42.62 & 42.35 & 42.78 & 42.53 & 39.42 & 47.09 & 43.34 \\
\hline & 0.8 & 49.75 & 47.13 & 48.26 & 47.34 & 49.35 & 42.49 & 51.63 & 48.14 \\
\hline & 0.7 & 53.88 & 50.27 & 51.64 & 50.41 & 53.84 & 46.32 & 55.76 & 52.36 \\
\hline & 0.6 & 55.06 & 52.99 & 52.38 & 52.59 & 54.70 & 49.32 & 58.90 & 55.89 \\
\hline & 0.5 & & 54.34 & & 54.12 & & 51.99 & & 58.66 \\
\hline & 0.4 & m $\overbrace{0}^{\Phi}-$ & 54.70 & m $\overbrace{\circlearrowright}^{\Phi}-$ & 55.28 & m \ & 54.5 & m $\overbrace{d}^{\Phi}-$ & 60.36 \\
\hline & 0.3 & & 50.80 & & 51.86 & & 59.15 & & 61.60 \\
\hline
\end{tabular}


Table 3. $V_{\mathrm{RMS}}$ (fundamental) for five level output voltage based on equal amplitude and unequal amplitude carriers with various modulation indices

\begin{tabular}{|c|c|c|c|c|c|c|c|c|c|}
\hline \multirow{3}{*}{ Ref. } & \multirow{3}{*}{$\mathrm{m}_{\mathrm{a}}$} & \multicolumn{8}{|c|}{$V_{\text {RMS }}$ (Fundamental) for 5-level inverter } \\
\hline & & \multicolumn{2}{|c|}{ PDPWM } & \multicolumn{2}{|c|}{ PODPWM } & \multicolumn{2}{|c|}{ APODPWM } & \multicolumn{2}{|c|}{ COPWM } \\
\hline & & PD & UEAPD & POD & UEAPOD & APOD & UEAAPOD & $\mathrm{CO}$ & UEACO \\
\hline \multirow{7}{*}{ 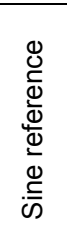 } & 1 & 70.63 & 76.7 & 70.51 & 76.85 & 70.32 & 76.79 & 70.63 & 77.5 \\
\hline & 0.9 & 63.52 & 71.97 & 63.29 & 71.96 & 63.52 & 71.91 & 63.52 & 72.89 \\
\hline & 0.8 & 56.42 & 67.19 & 56.52 & 67.27 & 56.42 & 67.13 & 56.42 & 68.25 \\
\hline & 0.7 & 49.2 & 62.04 & 49.21 & 62.13 & 49.2 & 65.05 & 49.2 & 63.63 \\
\hline & 0.6 & 42.17 & 57.21 & 42.36 & $57.24^{\circ}$ & 42.17 & 57.2 & 42.17 & 58.74 \\
\hline & 0.5 & & 52.07 & & 52.04 & & 52.03 & & 53.7 \\
\hline & 0.4 & 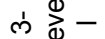 & 46.45 & m $\stackrel{0}{0}_{0}$ & 46.38 & 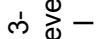 & 46.46 & 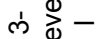 & 48.01 \\
\hline & 0.3 & & 39.83 & & 41.20 & & 41.30 & & 40.04 \\
\hline \multirow{7}{*}{ 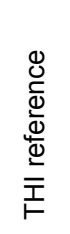 } & 1 & 81.85 & 84.53 & 81.81 & 84.46 & 81.73 & 84.43 & 84.17 & 84.73 \\
\hline & 0.9 & 73.66 & 78.74 & 73.63 & 78.83 & 73.6 & 78.75 & 78.75 & 79.54 \\
\hline & 0.8 & 65.37 & 73.41 & 65.44 & 73.22 & 65.39 & 73.39 & 73.59 & 74.29 \\
\hline & 0.7 & 57.08 & 67.78 & 57.09 & 67.78 & 56.98 & 67.82 & 67.97 & 69.17 \\
\hline & 0.6 & 48.78 & 62.34 & 48.8 & 62.2 & 48.87 & 62.23 & 61.31 & 63.92 \\
\hline & 0.5 & & 56.75 & & 56.63 & & 56.79 & & 58.47 \\
\hline & 0.4 & ले & 50.81 & ल่ \ - & 50.78 & ले & 50.79 & लं \ - & 53.01 \\
\hline \multirow{9}{*}{ 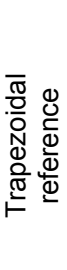 } & 0.3 & & 44.69 & & 44.79 & & 44.78 & & 46.05 \\
\hline & 1 & 82.84 & 84.94 & 82.82 & 84.92 & 82.86 & 84.96 & 84.63 & 85.24 \\
\hline & 0.9 & 74.46 & 79.41 & 74.56 & 79.38 & 74.41 & 79.36 & 79.26 & 79.98 \\
\hline & 0.8 & 66.11 & 73.77 & 65.89 & 73.77 & 66.12 & 73.75 & 73.66 & 74.72 \\
\hline & 0.7 & 57.75 & 68.17 & 57.92 & 68.19 & 57.59 & 68.14 & 68 & 69.5 \\
\hline & 0.6 & 49.35 & 62.63 & 49.36 & 62.59 & 49.4 & 62.61 & 61.95 & 64.02 \\
\hline & 0.5 & & 56.79 & & 56.71 & & 56.83 & & 58.59 \\
\hline & 0.4 & 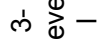 & 50.89 & 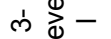 & 51.15 & ๗' $\gg_{0}^{\Phi}-$ & 50.87 & ๗' \} $&{52.87} \\
{\hline} &{0.3} &{ } &{44.76} &{ } &{44.67} &{ } &{44.62} &{ } &{46.62} \\
{\hline \multirow{8}{*}{\text { 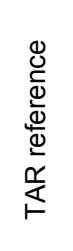 }}\text { 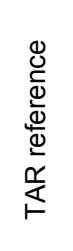 }} &{1} &{75.94} &{77.97} &{75.86} &{77.94} &{75.86} &{77.39} &{76.79} &{78.43} \\
{\hline} &{0.9} &{68.31} &{73.02} &{68.03} &{72.88} &{68.84} &{73.48} &{71.89} &{73.72} \\
{\hline} &{0.8} &{60.74} &{67.96} &{60.14} &{67.68} &{61.68} &{69.45} &{67.02} &{68.75} \\
{\hline} &{0.7} &{52.81} &{62.64} &{52.34} &{62.33} &{53.76} &{65.46} &{62.06} &{63.71} \\
{\hline} &{0.6} &{45.18} &{56.93} &{45.22} &{56.96} &{45.93} &{61.51} &{56.91} &{58.33} \\
{\hline} &{0.5} &{ } &{51.33} &{ } &{51.48} &{ } &{57.34} &{ } &{53.02} \\
{\hline} &{0.4} &{\text { ले } \stackrel{0}{\gg}-} &{45.61} &{\text { ले } \stackrel{0}{\otimes}-} &{45.46} &{\text { ウं } \stackrel{D}{0}_{0}^{\infty}} &{45.68} &{\text { लं } \stackrel{D}{0}_{0}} &{47.69} \\
{\hline} &{0.3} &{ } &{40.29} &{ } &{40.13} &{ } &{34.2} &{ } &{42.73} \\
$\hline
\end{tabular}

\section{Conclusion}

The proposed work compares the various pulse width modulation techniques for the chosen single phase half bridge DCMLI. For all the PWM strategies and references the UEAC produces less THD and higher fundamental RMS (Root Mean Square) values except for $m_{a}=1$. For $m_{a}=1$ the EAC provides less THD (Total Harmonic Distortion) and higher fundamental RMS (Root Mean Square) values for all the PWM methods and references. Table 2 and 3 displays the total harmonic distortion and output fundamental voltages for various PWM techniques and references.

\section{References}

[1] J Chiasson J, Tolbert LM, McKennzie K, Z Du. A complete solution to the harmonic elimination problem. IEEE Trans. On Power Electronics. 2004; 19(2): 491-499.

[2] Dixon Juan, Luis Moran. High level multistep inverter optimization using a minimum number of power transistors. IEEE Trans. on Power Electronics. 2006; 21(2): 330-337.

[3] Wells JR, Geng X, Chapman PL, Krein PT, Nee BM. Modulation based harmonic elimination. IEEE Trans. on Power Electronics. 2007; 22(1): 336-340.

[4] Urmila B, Subbarayudu D. Multilevel Inverters: A comparative study of pulse width modulation techniques. Journal of Scientific \& Engineering Research. 2010; 1(3): 1-5.

[5] Farid khoucha, Mouna Soumia Lagoun, Adelaziz Kheloui, Mohamed El Hachemi Benbouzid. A comparision of symmetrical and asymmetrical Three-phase $\mathrm{H}$-Bridge multilevel inverter for DTC Induction motor drives. IEEE Trans. Energy Conversion. 2011; 26(1): 64-72.

[6] Nami A, Zare F, Ghosh A, Blaabjerg F. A Hybrid Cascaded converter topology with series connected symmetrical and Asymmetrical Diode-Clamped H-Bridge cells. IEEE Transactions on Power Electronics, 2011; 26(1): 51-65.

[7] Kangarlu M.F, Babaei E, Laali S. Symmetric multilevel inverter with reduced components based on non-insulated dc voltage sources. IET on Power Electronics. 2012; 5(5): 571-581. 
[8] Kangarlu MF, Babaei E. A Generalized Cascaded Multilevel Inverter Using Series Connection of Sub multilevel Inverter. IEEE Transactions on Power Electronics. 2013; 28(2): 625-636.

[9] Babaei E, Alilu S, Laali S. A New General Topology for Cascaded Multilevel Inverters Based on Developed H-bridge. IEEE Transaction on Industrial Electronics. 2014; 61(8): 3932-3939.

[10] Babaei E, Laali S, Bayat Z. A Single-Phase Cascaded Multilevel Inverter Based on a New Basic Unit With Reduced Number of Power Switches. IEEE Trans. Power Electron. 2015; 62(3): 922-929. 